\title{
CONTRIBUIÇÃO AO ESTUDO DA MORFOLOGIA DA BANANEIRA \\ (Musa spp): Posição das Gemas nas Bases das Bainhas \\ Foliares da Planta *
}

\author{
Vicente de Paula Maia Santos Lima ** \\ SALIM SiMÃo $* * *$
}

\begin{abstract}
O presente trabalho foi realizado em Piracicaba, São Paulo, Brasil. Os autores fizeram observações sôbre a posição que as gemas ocupam na base das bainhas das fôlhas da bananeira e às quais estão associadas. Utilizaram o cultivar Musa (Grupo AAA, Sub-Grupo Cavendish) "Nanicão", classificado de acôrdo com a nomenclatura de SIMMONDS (1966).

Chegaram às seguintes conclusões: 1. As gemas associadas às bases das bainhas foliares estão colocadas em sua metade esquerda. 2. A metade direita das bainhas encobre as gemas colocadas mais internamente no caule da bananeira. 3. A disposição das gemas no caule é função da filotaxia da planta.
\end{abstract}

\section{INTRODUÇÃO}

A presente investigação foi realizada no ano de 1971, em um bananal existente na área de viveiro do Departamento de Agricultura e Horticultura da Escola Superior de Agricultura "Luiz de Queiroz", Piracicaba, São Paulo, Brasil. Seu objetivo se constituiu em tornar mais claro o que até hoje se tem escrito em relação a posição que as gemas da bananeira ocupam no caule verdadeiro da planta.

\section{REVISÃO DA LITERATURA}

BARKER (1959) diz que a bananeira inicia seu crescimento a partir de uma gema colocada na base de um rizoma, a qual forma um caule verdadeiro, curto, onde se originam novas gemas, arranjadas em uma espiral ascendente. Tais gemas são encontradas neste caule verdadeiro onde as margens de cada bainha foliar se encontram, formando um V característico; podem estar em um avançado estágio de

* Entregue para publicação em 31-12-1971.

** Professor Assistente do Departamento de Fitotecnia da Escola Superior de Agricultura de Mossoró; Bolsista da CAPES.

*** Professor Catedrático do Departamento de Agricultura e Horticultura da Escola Superior de Agricultura "Luiz de Queiroz". 
desenvolvimento quando associadas às fôlhas mais velhas e externas, ou podem ser rudimentares quando associadas às fôlhas mais jovens e internas.

BARKER \& STEWARD (1962) assinalaram que não há ocorrência de gemas axilares, mas que em decorrência de um comportamento anômalo e em situação oposta às folhas, se originam gemas adventícias, sub-epidermais, independentes do meristema principal, as quais poderão posteriormente se transformar em rebentos. A primeira conexão vascular de uma gema se dá com o primórdio da próxima folha que lhe é imediatamente superior no interior do caule da bananeira.

CHAMPION (1963) afirma que a bainha foliar envolve completamente o bulbo e que suas duas margens, muito delgadas, se reunem formando um $\mathrm{V}$ muito evidente, na ponta do qual se distingue uma gema pouco saliente, mas bem aparente. Ressalta ainda que a cada bainha corresponde uma gema, cada vez menor quanto mais interna for a folha que a sustenta.

SIMMONDS (1966) aponta que, externamente, o caule da banana é coberto com cicatrizes foliares muito compactadas, o que vale dizer que os entre-nós são extremamente curtos. Estas cicatrizes formam um anel completo em volta do caule verdadeiro e cada uma é associada com uma gema que lhe é oposta em posição, ou seja, as 'gemas não são axilares. Embora a base de cada folha esteja associada com uma gema, poucas delas se desenvolvem e é raro se ver mais do que três ou quatro gemas atingirem dimensões macroscopicamente visíveis em um único caule.

\section{MATERIAL E MÉTODO}

Bananeiras da variedade cultivada Musa (Grupo AAA, Sub-Grupo Cavendish) "Nanicão", classificada de acordo com a nomenclatura de SIMMONDS (1966), representaram o material utilizado na investigação.

O método adotado consistiu em cortar a lâmina foliar de uma planta na altura do pecíolo. A seguir afastou-se a bainha foliar do pseudo-caule e, com um canivete, efetuou-se sua divisão ao meio através de um corte longitudinal realizado de sua base para a extremidade. Observou-se assim a posição da gema associada à base desta bainha. Em seguida, as duas metades foram arrancadas a fim de que se pudesse observar a posição da gema encoberta pela bainha rasgada. Um corte em meia-lua foi efetuado sobre a gema associada à base da bainha rasgada, antes de seu rasgamento, com o objetivo de evitar a danificação da gema referida. O processo foi repetido com as bainhas mais internas, bem como em diversas plantas. 


\section{RESULTADOS E DISCUSSÃO}

Pelas descricões dos autores apresentados na revisão da literatura, supõe-se que a gema associada à base de uma bainha foliar esteja colocada nela em uma posição central, pois se acha no ponto de encontro das margens da bainha mais externa e em posição oposta à lâmina foliar que esta bainha sustenta (fig. 1) .

No entanto, face às observações realizadas, notou-se que a gema associada à base de uma bainha se encontra sempre em sua metade esquerda, ao passo que a metade direita encobre a gema colocada em posição mais interna no caule da bananeira, entre as margens da bainha seguinte e associada à base de uma terceira (fig. 2).
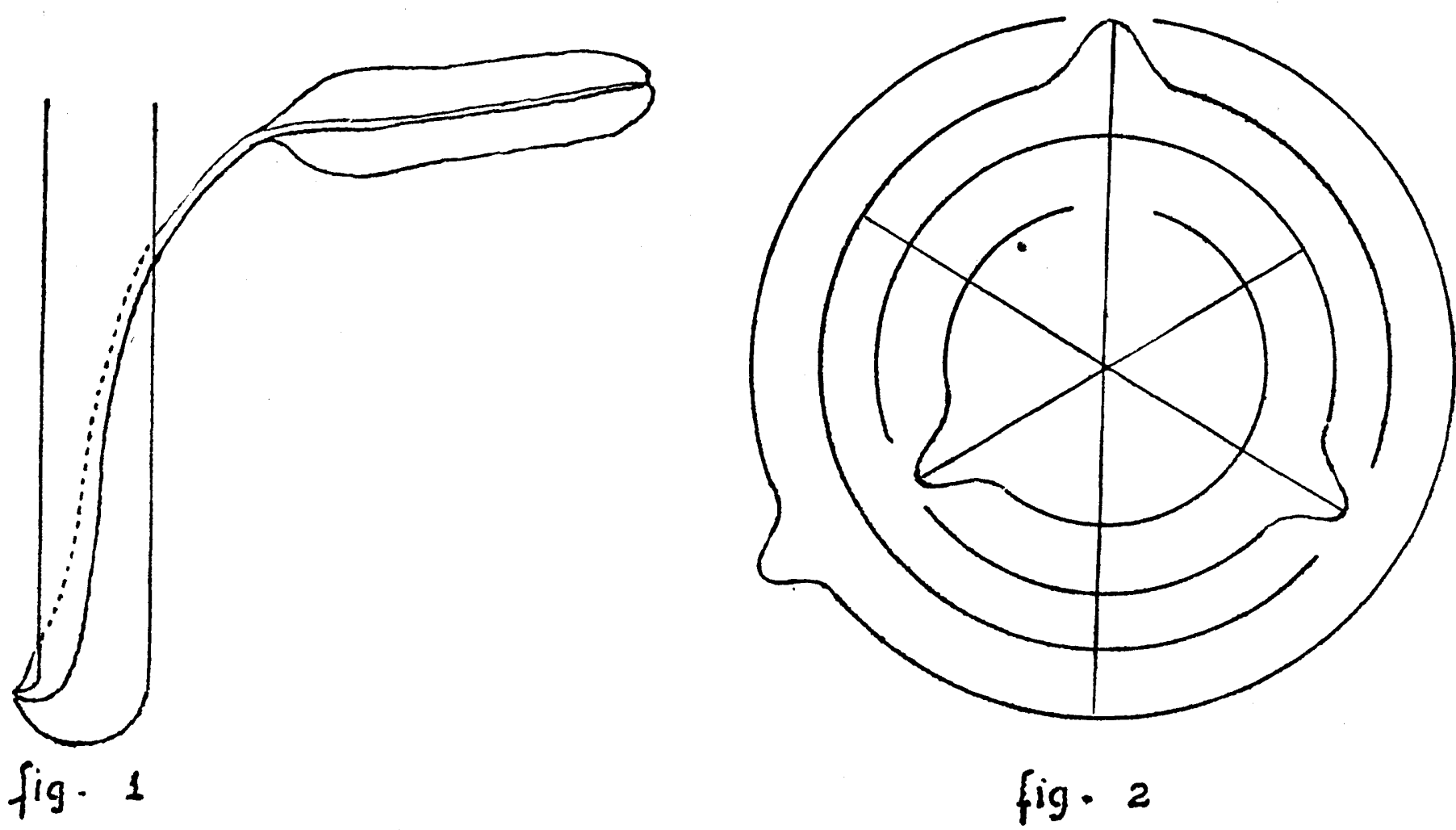

fig. 2

Este desenho representa a seç̧ão transversal do caule de uma bananeira, vendo-se as bainhas e as gemas associadas às suas; bases. É fácil de imaginar que, se as gemas estivessem colocadas nos centros das bainhas, as gemas e' as fôlhas estariam sempre dispostas em posição oposta, o que daria à planta um aspecto semelhante à Ravienala madagascariensis. Este fato, na realidade não ocorre, pois devido à própria filotaxia da planta, que dispõe as fôlhas no caule verdadeiro da bananeira obedecendo a uma helicoidal, as gemas também se dispõem em helicoide, partindo ambas as curvas no sentido da esquerda para a direita, quando se observa a planta de frente. 


\section{CONCLUSÕES}

1. As gemas associadas às bases das bainhas foliares da bananeira estão colocadas na metade esquerda das referidas bainhas.

2. A metade direita das bainhas encobre as gemas colocadas em posição mais interna no caule da planta. planta.

3. A disposição das gemas no caule é função da filotaxia da

\section{SUMMARY}

CONTRIBUTION TO THE STUDY OF THE MORPHOLOGY OF THE BANANA PLANT (MUSA SPP) : BUD POSITION ON THE LEAF SHEAT BASE OF THE PLANT.

In this paper, result of studies conducted in Piracicaba, São Paulo, Brazil, the authors made observations about the position of the buds at the base of the leaf sheaths to which they are associated. They used the banana plant variety Musa (AAA Group, Cavendish Sub-Group) "Nanicão", classified according to SIMMONDS' nomenclature (1966).

The following conclusions were drawn: (1) The buds at the base of the leaf sheaths are found on the left, at lateral position on the sheaths. (2) The right side of the sheaths covers the younger buds which are placed more internally on the banana stem. (3) The position of the buds in the banana stem is a function of the phyllotaxy of the plant.

\section{LITERATURA CITADA}

BARKER, W. G., 1959. A system of rapid multiplication of the banana plant. Trip. Aric. 36(4):275-284.

\& STEWARD, F. C., 1962. Growth and development of the banana $26(103): 389-411$.

CHAMPION, J., 1963. Le bananier. Paris, Maisonneuve et Larose, 264p.

SIMMMONDS, N. W., 1966. Bananas. 2nd. ed. London, Longmans, 512p. 
Composição e impressão

Tipografia FONSECA Ltda

Rua Coriolano, 962 - Lapa - SP 
